\title{
Acute Basilar Artery Occlusion in a Patient With Left Subclavian Artery Occlusion Due to First Rib Anomaly
}

\author{
-Case Report-
}

\author{
Rei YAmaguchi, Hideaki KOHGA*, Minori KurOSAKI*, Masaru TAMURA*, \\ Soukichi TANAKA*, Masahiko TOSAKA*, and Yuhei YOSHIMOTO
}

\begin{abstract}
Department of Neurosurgery, Gunma University Graduate School of Medicine, Maebashi, Gunma;
${ }^{*}$ Department of Neurosurgery, Fujioka General Hospital, Fujioka, Gunma
\end{abstract}

\begin{abstract}
A previously healthy 22-year-old man presented with thoracic outlet syndrome manifesting as Raynaud's phenomenon in the left hand and embolic occlusion of the basilar artery. Three-dimensional computed tomography angiography showed that the left subclavian artery was occluded as it passed over the abnormal first rib. Retrograde propagation of the thrombus from the site of arterial occlusion and/or reflux of embolic material was suspected. Medical therapy was started. The patient underwent resection of the anomalous rib. Postoperative angiography demonstrated that the subclavian artery was recanalized with almost normal distal flow. The basilar artery was also recanalized. Thoracic outlet syndrome due to a first rib anomaly may cause stroke.
\end{abstract}

Key words: cerebral embolism, first rib anomaly, thoracic outlet syndrome

\section{Introduction}

Thoracic outlet syndrome occurs when the neurovascular structures are compressed as they transverse the thoracic outlet, ${ }^{11)}$ which is defined by the first rib and scalenus muscles. ${ }^{2)}$ Nerve and vascular compression promotes Raynaud's phenomenon, pain, paresthesia, and motor weakness of the affected arm. ${ }^{5,13)}$ Prolonged compression of the subclavian artery results in fibrotic and inflammatory changes of the artery wall, which may extend to the intima and cause platelets aggregation, resulting in formation of mural thrombus, and macroembolism may cause digital gangrene. ${ }^{2,4)}$ Thromboembolism in thoracic outlet syndrome may rarely be associated with retrograde flow, which carries increased risk of cerebral embolism. ${ }^{1-3,8-10)}$ We report a case of thoracic outlet syndrome caused by a first rib anomaly resulting in embolism.

\section{Case Presentation}

A previously healthy 22-year-old man presented with Raynaud's phenomenon in the left hand. An or-

Received November 14, 2007; Accepted April 22, 2008 thopedic surgeon in our hospital made a diagnosis of thoracic outlet syndrome. Three-dimensional computed tomography (3D-CT) angiography showed an anomaly of the left first rib, which elevated the subclavian artery (Fig. 1). The anomalous rib lacked the anterior half and had assimilated at the center of second rib. Five months later, he suddenly suffered onset of vertigo, diplopia, dysarthria, motor weakness, and paresthesia on the left, and was transferred to our hospital. On arrival, he was somewhat somnolent and had no motor weakness, but the paresthesia and limb ataxia on the left still persisted. External ocular movements were normal with isocoric reactive pupils. Physical examination revealed a pulseless left radial artery. Hematological, biochemical, and serological examinations revealed no abnormalities suggesting vasculitis or coagulopathy. Twentyfour hour electrocardiography monitoring and transesophageal echocardiography also showed no abnormalities.

Magnetic resonance (MR) imaging revealed an infarction in the left cerebellar hemisphere and vermis (Fig. 2). The upper basilar artery was not visible on MR angiography (not shown). Immediate digital subtraction angiography also demonstrated distal basilar artery occlusion (Fig. 3). The bilateral superior cerebellar arteries were poorly opacified. Both 

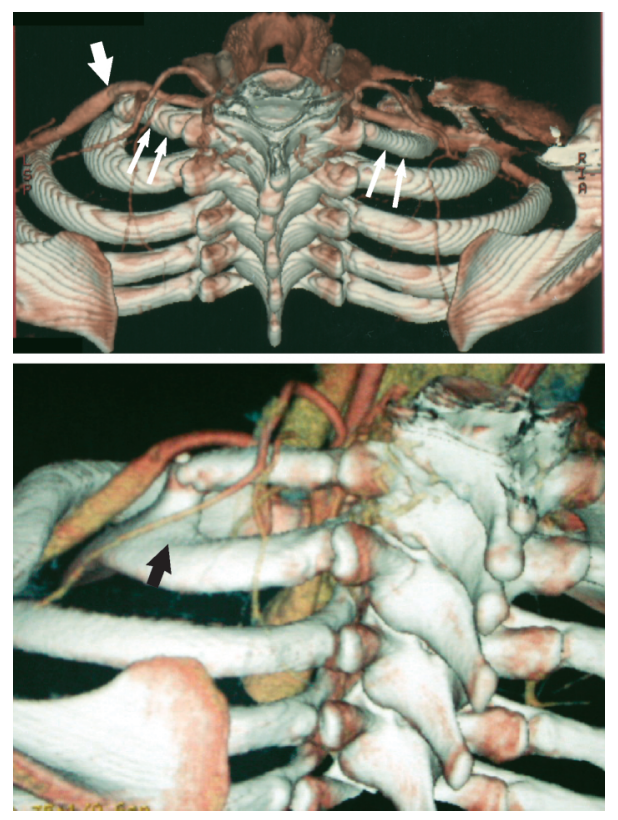

Fig. 1 Three-dimensional computed tomography angiograms (upper) revealing an anomalous upward course of the left first rib (arrows) and compression and elevation of the left subclavian artery (thick arrow), and (lower) showing the abnormal first rib lacked the anterior half and had assimilated with the second rib (thick arrow).

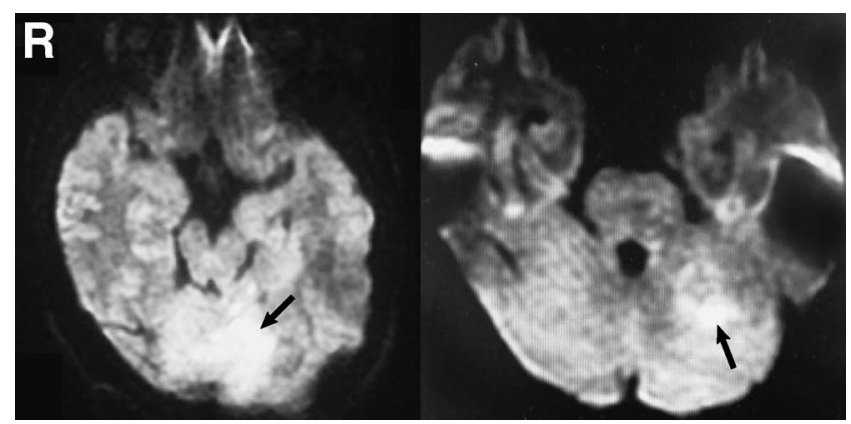

Fig. 2 Diffusion-weighted magnetic resonance images on admission showing cerebellar infarction (arrows).

posterior cerebral arteries were opacified through the posterior communicating arteries (not shown). The left subclavian artery was occluded as it passed over the abnormal rib, and poor run-off into the left axillary artery was observed through collateral flow via the left suprascapular artery branches (Fig. 4 left). A thrombus was identified within the subclavian artery. The aortic arch was normal. Embolic stroke originating from the occluded subclavian artery was suspected.

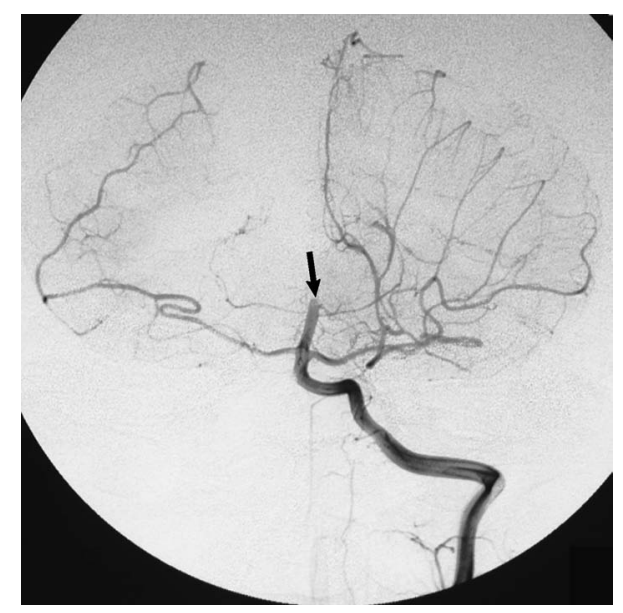

Fig. 3 Left vertebral angiogram showing occlusion of the distal basilar artery (arrow), very faint opacification of the bilateral superior cerebellar arteries, and large, anterior inferior cerebellar arteries feeding the upper half of the cerebellar hemisphere via leptomeningeal anastomoses.
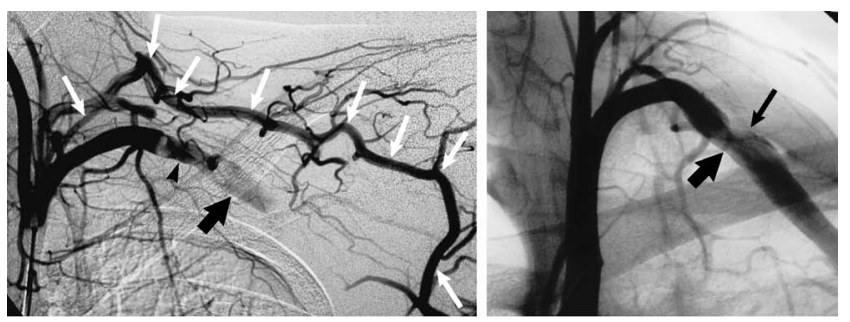

Fig. 4 Left subclavian angiogram (left) showing the subclavian artery completely occluded at the crossing point of the abnormal rib (thick arrow), a collateral channel to the axillary artery opacified through the enlarged suprascapular artery (arrows), and a thrombus within the subclavian artery (arrowhead). Postoperative angiogram (right) showing recanalization of the subclavian artery, but the mild stenosis (thick arrow) and poststenotic dilatation (arrow) still persisted, although the dilated collateral vessels had disappeared.

Heparin administration was started at $10000 \mathrm{U}$ per day, followed by ticlopidine and warfarin 1 week later. He recovered well and had almost no neurological deficit 2 weeks after the onset. The patient underwent surgery through the supraclavicular approach. The subclavian artery was severely compressed by the abnormal first rib. Poor pulsation of the distal artery was noted. Resection of 
Table 1 Clinical summary of 10 reported cases of cerebral infarction due to thoracic outlet syndrome

\begin{tabular}{|c|c|c|c|c|}
\hline Author (Year) & $\begin{array}{c}\text { Age } \\
\text { (yrs)/ } \\
\text { Sex }\end{array}$ & Symptoms & $\begin{array}{l}\text { Infarction } \\
\text { (affected } \\
\text { vessels) }\end{array}$ & Surgery \\
\hline \multirow{2}{*}{ Prior et al. $(1979)^{10)}$} & $36 / \mathrm{M}$ & lt hemiparesis & rt MCA & rt cervical rib resection \\
\hline & $21 / \mathrm{F}$ & $\begin{array}{l}\text { lt hemiparesis, } \\
\text { impaired vision }\end{array}$ & $\begin{array}{l}\text { rt carotid } \\
\text { artery area }\end{array}$ & rt cervical rib resection \\
\hline \multirow[t]{2}{*}{ al-Hassan et al. $(1988)^{1)}$} & $28 / \mathrm{M}$ & $\begin{array}{l}\text { lt hemiparesis, } \\
\text { lt facial nerve palsy }\end{array}$ & rt MCA & rt cervical rib resection \\
\hline & $36 / \mathrm{M}$ & lt hemiparesis & rt MCA & rt cervical rib resection \\
\hline Bearn et al. $(1993)^{2)}$ & $41 / \mathrm{M}$ & lt hemiparesis & rt MCA & $\begin{array}{l}\text { rt cervical rib resection, } \\
\text { graft replacement }\end{array}$ \\
\hline
\end{tabular}

BA: basilar artery, MCA: middle cerebral artery, VA: vertebral artery.

the bone resulted in recovery of arterial pulsation. Postoperative angiography demonstrated that the subclavian artery was recanalized with almost normal distal flow (Fig. 4 right). The basilar artery was also recanalized (not shown).

\section{Discussion}

Ten cases of cerebral infarction due to thoracic outlet syndrome have been reported, including our case (Table 1). ${ }^{1-3,8-10)}$ The cervical rib was the causative factor in all previous cases, in which the subclavian artery was compressed against the upper aspect of the first rib, just behind the distal insertion of the anterior scalene muscle. Anomalous first rib is another cause of arterial compression, but is much less common and was the cause of the syndrome in only $0.5 \%$ of cases. ${ }^{6)}$ In the present case, the first rib anomaly also caused cerebral embolism.

Cerebral embolism occurred as a consequence of right thoracic outlet syndrome in 8 of the 10 patients (Table 1). ${ }^{1-3,8-10)}$ Embolism originating from the right subclavian artery caused infarction in the carotid artery area in 6 of these 8 patients, rather than the vertebrobasilar artery area, probably due to the anatomical characteristics of the branching of the right carotid artery from the brachiocephalic artery and the differences in the caliber of this artery. Cerebral embolism from left thoracic outlet syndrome seems to be rare, with only 2 reported cases including the present case. ${ }^{10)}$ Ischemia in the vertebrobasilar artery area occurred in both patients (Table 1).
The diagnosis of thoracic outlet syndrome was based on radiography, Doppler ultrasonography, and angiography in all reported cases. ${ }^{1-3,8-10)}$ The recent development of less invasive imaging technology permits the diagnosis of various lesions with higher resolution. In this case, 3D-CT angiography demonstrated the anomalous course of the first rib clearly. The compression of the affected subclavian artery was also seen, and abnormal luminal configuration such as stenosis or post-stenotic dilatation is also frequently visible. Therefore, 3D-CT angiography is useful for the diagnosis of thoracic outlet syndrome. However, conventional angiography is still needed for the evaluation of the distal flow with collateral channels and the detection of an intraluminal thrombus, as observed in the present case.

Surgical treatment should be considered to prevent recurrence of embolisms. Removal of the anomalous bone is a standard procedure. ${ }^{12)}$ Additional arterial reconstruction should be performed in the presence of poststenotic dilatation or mural thrombus. ${ }^{2,6)}$ In this case, digital subtraction angiography 2 weeks after onset showed no mural thrombus in the subclavian artery. Therefore, subclavian artery reconstruction was not performed. Chronic inflammation of the arterial wall may cause aneurysm formation. Thromboembolic complications are significantly more common in arteries with aneurysmal dilatation. ${ }^{7)}$

Thoracic outlet syndrome caused by a first rib anomaly may cause stroke through retrograde 
propagation of a thrombus from the sites of arterial occlusion or the reflux of embolic material. 3D-CT angiography is useful for the detection of abnormal bony structures and vascular pathology of thoracic outlet syndrome.

\section{References}

1) al-Hassan HK, Abdul Sattar M, Eklof B: Embolic brain infarction: a rare complication of thoracic outlet syndrome. A report of two cases. J Cardiovasc Surg (Torino) 29: 322-325, 1988

2) Bearn P, Patel J, O’Flynn WR: Cervical ribs: a cause of distal and cerebral embolism. Postgrad Med J 69: 65-68, 1993

3) Blank RH, Connar RG: Arterial complications associated with thoracic outlet compression syndrome. Ann Thorac Surg 17: 315-324, 1974

4) Desai Y, Robbs JV: Arterial complications of the thoracic outlet syndrome. Eur J Vasc Endovasc Surg 10: 362-365, 1995

5) Haimovici H: Arterial thromboembolism of the upper extremity associated with the thoracic outlet syndrome. J Cardiovasc Surg (Torino) 23: 214-220, 1982

6) Hashimoto H, Nikaido Y, Kurokawa S, Miyamoto K, Sakaki T: [Thoracic outlet syndrome due to first rib anomaly: a case report]. No Shinkei Geka 22: 10631066, 1994 (Jpn, with Eng abstract)

7) Judy KL, Heymann RL: Vascular complications of thoracic outlet syndrome. Am J Surg 123: 521-531,
1972

8) Matsen SL, Messina LM, Laberge JM, Gordon RL, Kerlan RK Jr, Schneider DB: SIR 2003 film panel case 7: arterial thoracic outlet syndrome presenting with upper extremity emboli and posterior circulation stroke. J Vasc Interv Radiol 14: 807-812, 2003

9) Nishibe T, Kunihara T, Kudo FA, Adachi A, Shiiya N, Murashita T, Matusi Y, Yasuda K: Arterial thoracic outlet syndrome with embolic cerebral infarction. Report of a cases. Panminerva Med 42: 295-297, 2000

10) Prior AL, Wilson LA, Gosling RG, Yates AK, Ross Russell RW: Retrograde cerebral embolism. Lancet 2(8151): 1044-1047, 1979

11) Samarasam I, Sadhu D, Agarwal S, Nayak S: Surgical management of thoracic outlet syndrome: A 10-year experience. ANZ J Surg 74: 450-454, 2004

12) Sanders RJ, Pearce WH: The treatment of thoracic outlet syndrome: a comparison of different operations. J Vasc Surg 10: 626-634, 1989

13) Swinton NW Jr, Hall RJ, Baugh JH, Blake HA: Unilateral Raynaud's phenomenon caused by cervical-first rib anomalies. Am J Med 48: 404-407, 1970

Address reprint requests to: Rei Yamaguchi, M.D., Department of Neurosurgery, Gunma University Graduate School of Medicine, 3-39-15 Showa-machi, Maebashi, Gunma 371-8511, Japan.

e-mail: ryamaguc@showa.gunma-u.ac.jp 